\title{
ESTUDIOS
}

\section{El derecho mercantil entre la ética de los negocios y la responsabilidad social}

\section{Giacomo Bosi'}

Resumen: La cuestión de la ética de los negocios puede ser abordada tanto desde un punto de vista teórico, como atendiendo a las repercusiones prácticas que afectan a la fisiología y a la patología de la vida empresarial. En este texto se consideran tres visiones acerca de esta cuestión, que nacen del pensamiento de Vicenzo Buonocore: la primera atiende a la función social de la empresa; la segunda tiene en cuenta la organización interna y las vertientes decisionales de la empresa; por su parte, la última perspectiva de estudio se refiere a la organización de la actividad externa y al respeto del principio de legalidad por parte de la empresa. A partir de estas perspectivas individuales se intenta verificar si existe un nexo entre ellas, además de dar respuesta a algunos interrogantes relacionados con las mismas.

Palabras clave: ética de los negocios, responsabilidad social de la empresa.

Fecha de recepción: 7 de noviembre de 2011

Fecha de admisión definitiva: I 3 de marzo de 2012.

\footnotetext{
' Investigador de Derecho mercantil adscrito al Área de Derecho Mercantil del Departamento de Ciencias Jurídicas de la Universidad de Trento.

Agradezco al profesor José Manuel Serrano Cañas, Universidad de Córdoba, por la traducción del original italiano y la ayuda prestada para la elaboración del § 6. Los errores y omisiones, obviamente, deben imputarse sólo al autor.
} 


\section{Commercial law and business ethics and social responsibility}

\begin{abstract}
The issue of business ethics can be approached from both a theoretical point of view and as a response to the practical repercussions that affect the physiology and the pathology of corporate life. This text addresses three views on this issue, born in the reflections of Vicenzo Buonocore: the first addresses the social role of the company; the second reflects on the internal organization and decisional aspects of the firm; the last perspective of the study refers to the organization of external activity as well as to the company's respect for the principle of legality. From these individual perspectives there is an attempt to verify if there is any connection between them, and also to answer some related questions.
\end{abstract}

Key words: business ethics, social corporate responsibility.

\section{Le droit commercial: entre l'éthique des affaires et la responsabilité sociale}

Résumé: La question de l'éthique dans les affaires peut être abordée aussi bien du point de vue théorique que, par exemple, en observant les répercussions pratiques qui touchent la physiologie et la pathologie de la vie patronale. Dans ce texte nous considérons trois visions sur ce thème et qui naissent de la pensée de Vicenzo Buonocore: la première s'occupe de la fonction sociale de l'entreprise, la seconde prend en compte l'organisation interne et les tendances decisionnelles de l'entreprise; et en ce qui concerne la dernière perspective de l'étude, celle-ci se réfère à l'organisation de l'activité externe et au respect des principes de legalité de la part de l'entreprise. A partir de ces perspectives individuelles, nous essayons de vérifier $s^{\prime} i$ existe un lien entre elles, en plus de donner une réponse à certaines interrogations en rapport avec elles.

Mots clés: éthique des affaires; responsabilité sociale de l'entreprise.

\section{Premisas}

La cuestión de la ética (en sentido práctico) de los negocios puede ser abordada tanto desde un punto de vista teórico, como atendiendo a las repercusiones prácticas que afectan a la fisiología y a la patología de la vida empresarial. Vicenzo Buonocore ha propuesto una convincente visión tripartita de la ética de los nego$\operatorname{cios}^{2}$ que resulta interesante retomar y revisar en los términos que siguen. Así, en primer lugar, la cuestión de la ética de los negocios puede analizarse atendiendo

2 BUONOCORE, "Etica degli affari, impresa etica e impresa socialmente responsabile", en AA.VV. (2008) La responsabilità sociale dell'impresa, dir. Conte, Roma-Bari, p. 55 ss. 
a la función social de la empresa. En segundo lugar, se puede tener en cuenta la organización interna y las vertientes decisionales de la empresa. Una última perspectiva de estudio de la ética de los negocios haría referencia a la organización de la actividad externa y al respeto del principio de legalidad por parte de la empresa. En esta contribución tomaremos en consideración tales perspectivas individualmente y verificaremos qué nexo -en caso de que exista- une cada una con las demás. Asimismo, se intentará además dar respuesta a algunos interrogantes.

En cuanto a la primera visión de la ética de los negocios (relativa a la función social de la empresa), surge toda una serie de cuestiones que traen en origen un debate más amplio acerca de cuáles han de ser los intereses a perseguir por quienes en calidad de administradores o de gestores dirigen una sociedad de capital. Esto es, ¿̇es compatible con instancias más "sociales" una concepción del interés de la sociedad que viene identificado única y exclusivamente, por mor del dominante paradigma contractualista, con el interés en la maximización del valor de las acciones de la sociedad?

El segundo punto de vista propuesto como criterio de análisis de la ética de los negocios intenta llamar la atención acerca de la enorme complejidad del contexto en que el empresario debe adoptar sus decisiones gestoras, en el sentido de que carece por completo de auxilio legal alguno, al no existir norma jurídica específica y concreta que guíe la conducta a seguir en la toma de decisiones. Dicho con otras palabras, resulta necesario responder a la siguiente pregunta: $\dot{\imath}$ Con qué criterios es oportuno que dirijan los administradores o gestores la acción de su comportamiento en la toma de decisiones gestoras y qué sistema de administración y control son coherentes con la exigencia de llevar a cabo una gestión éticamente responsable?

En cuanto a la tercera perspectiva de análisis de la ética de los negocios, interesan el grado y la modalidad de interrelación organizativa que se generan entre la empresa, de un lado, y, por otro lado, las instituciones y los individuos particulares pertenecientes a la comunidad en la que opera. Esto es, ¿̇qué modelos de autorregulación deben estipularse en el seno de la sociedad mercantil-empresaria a fin de que se haga coincidir el respeto del principio de legalidad con la maximización del bien común de los sujetos involucrados por la actividad de la empresa?

Los ámbitos normativos que hemos mencionado también son relevantes para el análisis que realizamos en el presente trabajo de forma necesariamente sintética. En efecto, la primera perspectiva de estudio incide, aunque sea de forma tangencial, en la cuestión de la empresa ética y, por tanto, en el aspecto normativo de la responsabilidad social de la empresa, de la que hablaremos en el $\S 3$, después de 
haber esbozado (sub§ 2) una serie de cuestiones preliminares relativas al concepto de interés social (como interés de la sociedad mercantil que da forma y organización jurídicas a una empresa). La segunda perspectiva concierne a la cuestión de la ética de empresa, y comprende los aspectos normativos relativos a la aplicación de las teorías denominadas "stakeholder oriented" a la organización corporativa de la empresa, lo que trataremos en el $\S 4$. La tercera perspectiva hace referencia, fundamentalmente, a la relación entre principios y reglas de comportamiento económico, binomio cuya importancia emerge nítidamente cuando se valoren las expresiones de autorregulación empresarial y societaria, que aquí se expondrán en el $\S 5$. El $§ 6$ verifica en qué medida la citada tripartición conceptual puede ser útil para clasificar, en el ámbito normativo propio del ordenamiento español, las prácticas económicas conformes a los parámetros de la ética de los negocios y de la responsabilidad social de la empresa. El $§ 7$ sintetiza y concluye.

\section{Los intereses sociales de la empresa ${ }^{3}$}

La razón por la que el concepto de interés social ha sido especialmente estudiado, tanto que se puede hablar de "teorías sobre el interés social", estriba fundamentalmente en el hecho de que el examen de su noción es imprescindible para reconstruir los supuestos de hecho sobre los que recaen el ámbito objetivo de aplicación de distintas normas del Derecho de sociedades. Sin embargo, el concepto de interés social abarca una reflexión jurídica de mayor alcance y calado. Bajo la fisonomía de este concepto jurídico se cobijan no sólo las normas que expresamente lo contemplan, sino también otras instituciones de Derecho de sociedades que concretan el modo en que el tipo sociedad anónima viene delineado en diversos contextos jurídicos. Pensemos, por ejemplo, en las normas existentes en materia de modelos de "governance", con referencia específica a la "ratio" subyacente al sistema dualístico de administración ${ }^{4}$, o en las normas en materia de transmisión del control o,

\footnotetext{
${ }^{3}$ En este estudio, el significado de interés social se corresponde con el interés de la empresa societaria. Se trata de un concepto técnico-jurídico propio del Derecho de sociedades mercantiles que conecta problemáticamente con la exigible función económica y social de la empresa societaria y que sirve de paradigma valorativo de la conducta decisional y gestora de los administradores sociales de dicha empresa societaria, los cuales están firmemente sujetos al deber de promover y velar en todo momento, con diligencia y lealtad, por el interés social, esto es, de la empresa que gestionan, al que se contrapone - puede contraponerse el interés particular de los accionistas (Nota del traductor).

${ }^{4}$ Por "sistema dualístico de administración" ha de entenderse aquel que estructura el órgano de gestión y representación de la sociedad mediante su división en dos subórganos: la Dirección y el Consejo
} 
incluso, en las normas introducidas para dar sustancia y contenido jurídicos a los deberes fiduciarios imputables y exigibles a los administradores sociales ${ }^{5}$.

Este conjunto de normas jurídicas se ve indirectamente influenciado por la concepción de interés social mayoritariamente aceptada en cada concreto ordenamiento jurídico y en cada momento histórico. Sabido es que son dos los polos en torno a los cuales giran las teorías del interés social: las teorías institucionalistas, por un lado, y las teorías contractualistas, por otro. Según las visiones institucionalistas, el interés social no puede identificarse con el interés de los socios. Se concibe, en efecto, como un interés distinto, superior al de los socios: el interés de la sociedad o de la empresa en sí misma considerada. Lo cual no obsta para que ambos intereses (el de la sociedad e interés de los socios) puedan coincidir ocasionalmente. Lo relevante es que se trata de un interés no disponible por los socios (ni siquiera mediando unanimidad). Por el contrario, las teorías contractualistas afirman que el interés social coincide con el interés común de los socios individuales ${ }^{6}$.

de control. Normalmente, corresponde a la dirección las facultades de gestión y representación de la sociedad, mientras que el consejo de control tiene como misión fundamental fiscalizar la actuación de la dirección. Cabe así establecer que determinadas operaciones gestoras se sometan a su autorización. Este sistema orgánico dual ha sido recepcionado en el ordenamiento jurídico español como consecuencia de la ley 19/2005, de 14 de noviembre, sobre la sociedad anónima europea domiciliada en España. Este nuevo tipo social se encuentra regulado en el Reglamento (CE) 2157/2001, de 8 de octubre de 2001, completado por la Directiva 2001/86/CE de la misma fecha, así como por los arts. 455 a 494 LSC española. (Nota del traductor).

${ }^{5}$ Véanse los arts. 225 y ss. de la Ley de sociedades de capital española (fundamentalmente el art. 226 LSC relativo al ahora denominado deber de lealtad -antes, deber de fidelidad- en cuya virtud los administradores desempeñarán su cargo como un representante leal en defensa del interés social, entendido como interés de la sociedad, y cumplirán los deberes impuestos por las leyes y los estatutos. (Nota. del traductor).

${ }^{6}$ Los dos grupos de teorías que hemos presentado -institucionalistas y contractualistas- pueden ser objeto de un estudio más específico siguiendo, por ejemplo, el esquema analítico propuesto por Disiano Preite. Se trata de un itinerario conocido pero que merece ser sintéticamente recordado. En primer lugar, dentro de las teorías institucionalistas, se puede distinguir, fundamentalmente, un grupo de teorías para las que el interés social viene constituido por una síntesis (si bien, difícilmente identificable) entre el interés común de los socios y el de otros sujetos como pueden ser los trabajadores de la empresa, los inversores/ahorradores, los socios futuros o los acreedores de la sociedad. Asimismo, nos encontramos con otro conjunto de teorías igualmente institucionalistas que por interés social entienden o bien el interés de la empresa identificado en su crecimiento económico y en la maximización del beneficio, en función exclusiva del interés de la economía nacional, o un interés superior al de la sociedad (empresa mercantil) que coincidiría con un interés diríase común a todos los socios, pero que se protege prescindiendo de la voluntad de los propios socios. En segundo lugar, dentro de las tesis contractualistas, se pueden distinguir, sobre todo, aquellas teorías que, si bien admiten la existencia de una pluralidad de intereses sociales, retienen relevante uno solo, a los fines de la aplicación de los 
Es necesario, sin embargo, precisar un poco más, aunque sea brevemente. Cuando mencionamos las teorías contractualistas no se quiere hacer referencia a la fuente originadora de la relación societaria, puesto que se sobreentiende y se admite sin más que la sociedad anónima nace de un contrato; ni tampoco se intenta indicar la naturaleza de la disciplina integradora de la sociedad anónima, ya que, en este punto, rigen los principios jurídicos emanados de cada uno de los diversos contratos implicados en y por la actividad de la empresa, de las normas relativas a la organización de la empresa, o de ambos. Muy al contrario; por teorías contractualistas se quiere hacer referencia a la noción específica del interés social identificable en los términos expuestos en este trabajo, y al modo en que tal concepto puede influir eventualmente en otros ámbitos normativos reguladores de la sociedad anónima.

citados arts. 2373 y 2441 del Código civil italiano. El art. 2373 Código civil italiano, en la rúbrica "conflicto de intereses", dispone que

[1] El acuerdo aprobado con el voto determinante de los socios que tengan, por cuenta propia o de terceros, un interés en conflicto con el de la sociedad puede ser impugnado ex art. 2377 siempre que sea susceptible de provocar un daño. [2] Los administradores no pueden votar los acuerdos relativos a (la exigencia de) su responsabilidad. Los componentes del Consejo de gestión no pueden votar los acuerdos relativos a su nombramiento, revocación o la responsabilidad de los miembros del consejo de vigilancia.

Este artículo, parangonable al art. 204 de la Ley de Sociedades de Capital española (en adelante, LSC) que permite la impugnación de los acuerdos sociales que (...) lesionen el interés social en beneficio de uno o varios socios o de terceros, establece la denominada prueba de resistencia (prova di resistenza), en el sentido de que para poder hacer valer esta causa de impugnación es necesario demostrar el carácter decisivo del voto emitido por el socio afectado por el conflicto de intereses, así como el (al menos potencial) carácter perjudicial de la decisión. En cuanto al art. 2441 Código civil italiano, en su quinto párrafo, al igual que el art. 308 LSC española, admite la posibilidad de excluir o limitar (según la regulación italiana) o suprimir total o parcialmente (como expresa la Ley española) el derecho de suscripción preferente (denominado por el Código civil italiano como derecho de opción) surgido en caso de aumento de capital con emisión de nuevas acciones o en caso de emisión de obligaciones convertibles en acciones, cuando así lo exija el interés de la sociedad (Nota del traductor)].

Entre estas teorías contractualistas, destacan, fundamentalmente, aquellas para las que el interés social comprende en realidad una pluralidad de intereses. Al mismo tiempo, podemos reconocer otras diferentes teorías contractualistas. Así, en particular, nos encontramos con aquellas teorías que inciden en la relevancia de un único interés social entendido como interés común de los socios en cuanto socios; con otras que dan relevancia a la existencia de un único interés social entendido como interés extrasocial de los socios. Incluso en el seno de este último grupo, podemos individualizar la existencia de otras tesis. En particular, se diferencia entre las teorías que otorgan relevancia a la existencia de una pluralidad de intereses sociales entendidos como el conjunto de todos los intereses comunes a los socios; y aquellas teorías que apuntan a la relevancia de una pluralidad de intereses sociales como el conjunto de todos los intereses (incluso aquellos en conflicto recíproco) del socio en cuanto parte del contrato social; cfr. PREITE, "Abuso de maggioranza e conflitto di interessi del socio nelle società per azioni", en AA.VV. (31993) Trattato delle società per azioni, dir. COLOMBO e PORTALE, Turín, p. 9 ss. 
En primer lugar, surge la necesidad de determinar cuál es la teoría recogida y aceptada en y por el Derecho societario que se encuentra "positivizado" en la mayor parte de los Estados de la Europa continental. Pues bien, las teorías institucionalistas han sido tradicional y mayoritariamente excluidas. La razón de su exclusión estriba en que por regla general los ordenamientos jurídicos no han articulado instrumentos jurídicos con los que los titulares de los distintos intereses que confluyen en la empresa (trabajadores, ahorradores/inversores, futuros socios, acreedores) puedan defender sus intereses frente a la sociedad y puedan oponerse a (esto es, impugnar) los acuerdos de los órganos societarios que puedan lesionarlos. Por tal razón, se llega a la conclusión de que no se reconoce en el Derecho italiano la posibilidad de tutelar el interés de la sociedad mercantil por parte de los administradores sociales, prescindiendo de la voluntad de los socios.

Por otra parte, entre los motivos que refuerzan el rechazo a las tesis institucionalistas ha de incluirse el paulatino abandono de la concepción de la sociedad como persona jurídica (esto es, sujeto de derecho) distinta de los socios, es decir, la idea por la cual los socios en su relación con la sociedad constituyen un mero órgano social. Entiéndase bien, de la calificación de la sociedad anónima como persona jurídica no se puede concebir sin más una noción de interés social como un interés distinto del interés de los socios, es decir, como un interés de "otra" persona diferente a la persona de los socios.

Pese a ello, de la exposición de los hechos que hasta este momento hemos realizado nada nuevo se ha avanzado en la labor de concreción y delimitación del concepto de interés social. No obstante, de estas conclusiones parciales es posible realizar una enumeración de toda una serie de intereses propios de los socios (o, si se nos permite la expresión, intereses sociales típicos) que tradicionalmente se derivan de las normas jurídico-positivas que componen el Derecho societario italiano actual. Así, podemos enumerar los siguientes intereses sociales: (a) el interés en la maximización del beneficio social; (b) el interés en la percepción de los dividendos en el curso de la actividad social; (c) el interés en participar y controlar la gestión de la sociedad; (d) el interés en la conservación del nivel de influencia en la gestión social incluso en presencia de variaciones del capital y en la conservación del valor de la propia cuota en caso de entrada de nuevos socios; (e) el interés en la determinación del grado de riesgo de la actividad social; $(f)$ el interés en la determinación de la duración de la propia inversión atendiendo a las propias exigencias económicas personales; $(f)$ el interés en la transmisión de la propia participación social. En todos estos casos, como apunta la doctrina más tradicional, la junta general se erige, "durante societate", como el verdadero intérprete institucional protector de todos estos intereses pertenecientes a los socios 
en cuanto partes del contrato social (intereses que, no se olvide, pueden estar potencialmente en conflicto). Serán las relaciones de fuerza dominantes en cada tiempo y contexto las que -se entiende- determinarán "de facto" qué intereses van a prevalecer.

Esta enumeración esquemática permite comprender por qué y en qué medida las conclusiones obtenidas en relación a la cuestión del interés social han influenciado negativamente (en el sentido de empequeñecer y empobrecer) el debate relativo a la aceptación de vínculos normativos relativos a criterios de responsabilidad social de la empresa y, por ende, han condicionado la posibilidad de que este tipo de responsabilidad pueda alcanzar la categoría de verdadero supuesto de hecho en sentido técnico-jurídico. Por otra parte, en la actualidad no faltan significativas tomas de posiciones que invitan a superar de manera progresiva una visión de neta oposición de las teorías contractualistas e institucionalistas. Parece oportuno, pues, hacer una breve referencia.

Renzo Costi ha sido uno de los pioneros en intentar superar esta tensión dialéctica entre ambas visiones del interés social. En efecto, para el Prof. Costi, partiendo de una tesis netamente contractualista, toda empresa por el mero hecho de ser empresa capitalista no tiene propiamente como finalidad la persecución de otros intereses distintos a la maximización del beneficio de los accionistas. No obstante y pese a ello, llega a afirmar que

[la] autonomía estatutaria, respetando el requisito de economicidad de la empresa, puede limitar el fin de lucro, consintiendo o imponiendo que la persecución del mismo deba llevarse a cabo respetando los intereses de partes interesadas distintas de los accionistas ${ }^{7}$.

Este mismo autor, en un análisis más general, ha contribuido a una aclaración conceptual y sistemática entre ambas visiones del interés social, estableciendo una útil distinción entre acepción débil y acepción fuerte del institucionalismo. La primera noción, la débil, es aquella que no abarca todos los intereses perseguidos por la empresa. Nace por la consciencia adquirida en el seno de la sociedad, en el sentido de que

si bien es cierto que la sociedad debe perseguir sólo el interés de los socios y no el de los demás stakeholder, no obstante la sociedad se materializa en una organización que da vida a una serie de relaciones entre los socios y entre éstos y los administradores; esta red de normas, teniendo como presupuesto un contrato de sociedad o un acto unilateral

7 Así, Costı, "La responsabiliłà sociale dell'impresa e il diritto azionario italiano", en AA.VV. (2006) La responsabilità dell'impresa, Milán, Giuffrè, p. 113. 
de constitución, no encuentra en la teoría general del contrato $y$, en particular, en el contrato de cambio, un régimen satisfactorio ${ }^{8}$.

Por tanto, la acepción débil del concepto de institucionalismo se basa en un aspecto eminentemente reglamentista, relativo a la naturaleza de las normas que socios y gestores deben perseguir para realizar el interés de los socios. Sobre este aspecto del análisis - a partir de consideraciones ya hechas, que compartimos "in toto"volveremos en el $\S 5$.

En este mismo sentido, se pueden traer a colación de forma resumida otras posiciones doctrinales igualmente interesantes. Gastone Cottino, por ejemplo, ha tenido ocasión de enfatizar la presencia de gérmenes y elementos de naturaleza institucionalizante9 que conducen a un debilitamiento del citado dualismo. De forma análoga, Paolo Montalenti se encuentra

[p]ersonalmente (...) convencido de que la contraposición entre institucionalismo y contractualismo debe entenderse superada y debe hoy afirmarse una concepción dialéctica -en el sentido técnico del término- del interés social como composición de intereses de los accionistas e intereses de los stakeholders ${ }^{10}$.

Tal concepción dialéctica, como veremos en seguida, se ha visto ya reflejada en el debate sobre la elaboración de los conceptos de empresa ética y de empresa socialmente responsable.

\section{La empresa ética}

Antes de ilustrar las distintas modalidades que presentan los mencionados condicionamientos, resulta oportuno constatar la diferencia existente entre dos distintas dimensiones normativas: empresa ética, por un lado, y ética de la empresa, por otro lado (esta última dimensión se tratará en el $\S 4$ del presente trabajo). Una parte de la doctrina suele identificar como "ética" aquella empresa que con aten-

\footnotetext{
${ }^{8}$ Así, Costi, L'interesse sociale nella reforma del diritto azionario, estudio en curso de publicación y que ha sido posible consultar gracias a la cortesía del autor.

9 Así, Comino, "Contrattualismo e instituzionalismo. (Variazioni sul tema da un spunto di Giorgio Oppo)", en (2005) Rivista delle Società, p. 708-709.

${ }^{10}$ Así, MONTALENTI (2009) Crisi finanziaria, struttura dell'impresa, corporate governance, ODC-Roma, 20 giugno, en www.orizzontideldirittocommerciale.it, p. 4.
} 
ción prioritaria ha seleccionado su propio ámbito de actuación en el mercado de forma que se desprenda,

casi como natural consecuencia, la elección de la centralidad de la persona como protagonista y destinatario, cualesquiera que sean las semblanzas, de la actividad de empresa (...). [L]a elección de esta forma de actuación en el mercado y la elección de la centralidad de la persona vienen a significar que la empresa debe dedicarse a la producción de bienes o de servicios que sean útiles a la vida de la persona y que-aunque parezca casi superfluo revelarlo- se inserten en una dimensión productiva plenamente lícita. La presencia de las primeras dos características será tanto más apreciable si se realiza en positivo, a través de la elección de una actividad económica de particular valor social, como la enseñanza, el arte, la conservación y la valorización de los bienes culturales y ambientales, la asistencia a las categorías sociales más débiles ${ }^{11}$.

Otra parte de la doctrina, que más adelante analizaremos con mayor detalle, entiende necesario destacar cómo empresa ética y empresa socialmente responsable no son conceptos exactamente superpuestos ${ }^{12}$. Existen, así, tantas tipologías de empresa ética cuantas sean las teorías éticas formuladas, de forma que coincidirán ambas nociones sólo en el seno de algunas de estas teorías. La puntualización resulta nítida e indiscutible. Por otra parte, ha de tenerse en cuenta el hecho de que, si bien es cierto que no todas las empresas éticas son socialmente responsables, sin embargo, todas las empresas socialmente responsables se encuentran entre el elenco de empresas éticas ${ }^{13}$. En efecto, como la praxis ha consolidado, no cabe

11 Así, BuONOCORE, (nota 1), p. 66.

${ }^{12}$ Costi, (nota 9), p. 83 ss.

${ }^{13}$ En este punto, ha de llamarse la atención acerca de la positivación en el Ordenamiento jurídico español de un marco jurídico propio para aquellas empresas que desarrollan políticas de Responsabilidad Social de las Empresas. En efecto, la Ley 2/201 1, de 4 de marzo, de Economía Sostenible, en su capítulo VI (que lleva por rúbrica la Responsabilidad Social de las Empresas), dedica un artículo, el art. 39, para coadyuvar a la "Promoción de la responsabilidad social de las empresas". Así, según este art. 39 de la Ley de Economía Sostenible,

1. Con el objetivo de incentivar a las empresas, organizaciones e instituciones públicas o privadas, especialmente a las pequeñas y medianas y a las empresas individuales, a incorporar o desarrollar políticas de responsabilidad social, las Administraciones Públicas mantendrán una política de promoción de la responsabilidad social, difundiendo su conocimiento y las mejores prácticas existentes y estimulando el estudio y análisis sobre los efectos en materia de competitividad empresarial de las políticas de responsabilidad social. En particular, el Gobierno pondrá a su disposición un conjunto de características e indicadores para su autoevaluación en materia de responsabilidad social, así como modelos o referencias de reporte, todo ello de acuerdo con los estándares internacionales en la materia. 2. El conjunto de características, indicadores y modelos de referencia a que se refiere el apartado anterior deberá atender especialmente a los objetivos de transparencia en la gestión, buen gobierno corporativo, compromiso con lo local y el medioambiente, respeto a los derechos humanos, mejora de las relaciones laborales, promoción de la integración de la mujer, de la igualdad efectiva entre mujeres y hombres, de la igualdad de oportunidades y accesibilidad universal 
discutir que la responsabilidad social de la empresa gira en torno a la "exigencia" de actuación conforme a determinados "standards" mercadotécnicos y económicos (productivos, distributivos, organizativos, ocupacionales, etc.) preconstituidos por instituciones y entes supranacionales tendentes a individualizar e identificar un prototipo -o una serie de prototipos- de empresa ética ${ }^{14}$.

Para poder simplificar en este punto la delimitación conceptual de los fenómenos objeto de nuestro estudio, atendiendo a la variedad de las distintas vertientes expuestas, podemos partir de las categorías propuestas por Vicenzo Buonocore.

Así pues, antes de nada resulta necesario contrastar la idea de empresa ética con el pensamiento mencionado "retro" acerca de la materia del interés social. Sobre este punto se considera que, como hemos anticipado,

\begin{abstract}
de las personas con discapacidad y del consumo sostenible, todo ello de acuerdo con las recomendaciones que, en este sentido, haga el Consejo Estatal de la Responsabilidad Social Empresarial, constituido por el Real Decreto 221/2008, de 15 de febrero, por el que se regula el Consejo Estatal de Responsabilidad Social de las Empresas. 3. Las sociedades anónimas podrán hacer públicos con carácter anual sus políticas y resultados en materia de Responsabilidad Social Empresarial a través de un informe específico basado en los objetivos, características, indicadores y estándares internacionales mencionados en los apartados anteriores. En todo caso, en dicho informe específico deberá constar si ha sido verificado o no por terceras partes. En el caso de sociedades anónimas de más de 1.000 asalariados, este informe anual de Responsabilidad Social Empresarial será objeto de comunicación al Consejo Estatal de Responsabilidad Social Empresarial que permita efectuar un adecuado seguimiento sobre el grado de implantación de las políticas de Responsabilidad Social Empresarial en las grandes empresas españolas. Asimismo, cualquier empresa podrá solicitar voluntariamente ser reconocida como empresa socialmente responsable, de acuerdo con las condiciones que determine el Consejo Estatal de Responsabilidad Social Empresarial. 4. El Gobierno facilitará los recursos necesarios para que el Consejo Estatal de Responsabilidad Social Empresarial pueda llevar a cabo plenamente sus funciones". (Nota del traductor).
\end{abstract}

${ }^{14}$ Se pueden distinguir y ampliar tres tipos de prácticas que las empresas llevan a cabo en el intento de conformar su comportamiento a las mencionadas conductas socialmente responsables. En primer lugar, destaca sobremanera la práctica de aquellas empresas que explotan las potencialidades de la responsabilidad social simplemente como un mero revestimiento de "marketing"; en segundo lugar, la práctica de aquellas empresas que así se comportan porque se ven constreñidas por la presión sociopolítica, o porque lo consideran conveniente por un mero cálculo económico en términos de beneficios previsibles derivados del éxito en el mercado de este comportamiento; en tercer lugar, la práctica de aquellas empresas verdadera e íntegramente convencidas y comprometidas en el seguimiento de valores éticos, que resultan así efectivamente interiorizados en las distintas vertientes empresariales y gerenciales. Es importante que todos los tipos citados se manifestasen en el contexto de un consenso civil y empresarial, considerando el hecho de que las empresas más prudentes pueden desarrollar funciones de "starter" en beneficio de otras, en un mercado en que se deben identificar los sujetos que no asumen comportamientos cooperativos no necesariamente siguiendo a los "no cooperadores", sino más bien como [sujetos] cautos (...), que pueden ser "activados" por prácticas de gratuidad; así BRUNI (2006) Reciprocità: Dinamiche di cooperazione economica e società civile, Milano, Giuffrè, Mondari, p. 183. 
[I] vo voluntariedad de la asunción de responsabilidad frente a stakeholders distintos de los accionistas no excluye, sin embargo, que cada concreta empresa pueda comprometerse a aplicar un sistema individualizado de responsabilidad social en los términos propios del modelo institucional o en los del modelo de governance de naturaleza contractualista en sentido amplio. En tal caso, se deberá verificar si las modalidades que se intentan adoptar son compatibles con nuestro ordenamiento societario ${ }^{15}$.

Tal conclusión, por tanto, es coherente con las posiciones expresadas en materia de interés social que hemos expuesto al final del parágrafo precedente. Se percibe, además, que este último aspecto, o sea la vertiente eminentemente organizativa de la sociedad (que trata, al menos, de obtener el reconocimiento como empresa socialmente responsable), constituye el objeto del siguiente parágrafo en cuanto allí se abordará la cuestión de la ética de empresa -que por razones sistemáticas entendemos que es preciso realizar un tratamiento por separado-.

Con tales premisas, la cuestión de la responsabilización social de la empresa, esto es, la verificación de imputar responsabilidad a aquella empresa que no se comporte según un parámetro de conducta ética (en el sentido ya expresado), ha de descomponerse, como es ya tradicional, según se trate de grandes empresas -y en particular de las sociedades denominadas multinacionales- 0 de empresas de mediana o pequeña dimensión.

Comencemos por las primeras. Las grandes empresas continuamente son invitadas a adherirse a múltiples actos y convenios internacionales que estigmatizan conductas societarias nocivas en relación con el medio ambiente, la salud, los derechos de las personas desfavorecidas y de los derechos humanos en general. De este fenómeno tan sólo nos interesa una única dimensión, que no es otra sino la relativa a las repercusiones societarias que conlleva la adopción por parte de las empresas de tales obligaciones; esto es, la cuestión de si el contrato de sociedad responde, constituye o garantiza un verdadero instrumento de equilibrio entre los intereses de la empresa y los intereses de los "stakeholders". Téngase presente que para dar cumplimiento al contrato social de forma congruente con las citadas resoluciones hará falta utilizar otros instrumentos jurídicos (ejemplificando, podemos mencionar la formalización de la visión ética y de la misión de la empresa, así como la adopción de códigos éticos, la práctica de "training" ético, sistemas organizativos de implementación y control, instrumentos de control externo, etc.). De entre ellos, destacan sobre todo los códigos éticos que, por razón de su potencial densidad normativa, parece oportuno dedicarles algún párrafo. En la adopción de un código ético propio, en efecto,

${ }^{15}$ Así Costı, (nota 9), p. 94. 
(...) la empresa tiene frente a ella una vasta elección, siendo capaz de reelaborar, de forma más o menos discrecional, una pluralidad de modelos, líneas-guía, colecciones de buenas prácticas (best practices), maduradas a través de asociaciones empresariales o de instituciones internacionales que integran los principios de la denominada Corporate Social Responsibility, preparando posteriormente informes que ilustran las actuaciones eventualmente acometidas en esta dirección ${ }^{16}$.

Desde un punto de vista de carácter económico-institucional se atribuye a los códigos éticos una precisa función de "governance": coordinar la actividad económica de una empresa individual, o de un complejo de empresas, mediante la formalización de "benchmarks" de comportamiento. Ha de tratarse de "standards" de comportamiento que, a fin de ser tenidos en cuenta en la programación de la política empresarial, deben compartirse desde el comienzo, al menos en cierta medida; además debe existir también incentivos para su cumplimiento (ya se basen en valoraciones de eficiencia económica, en razones morales de fondo o, incluso, en la mera conveniencia de no incurrir en sanciones reputacionales derivadas de su incumplimiento). Es necesario, además, que el contenido ético de los códigos cuente con un mínimo nivel de difusión. Esta exigencia divulgativa se presenta, tradicionalmente, como condición previa ineludible de la eficacia operativa de los códigos de conducta y posibilita, a su vez, la consecución de dos objetivos: por una parte, permite que su contenido y formulación no se conviertan en verdadera "letra muerta", vacía de cualquier viso de realidad; por otra, evita que los códigos de conducta sean utilizados como instrumento de imposición de una cultura empresarial destinada a permanecer sustancialmente ajena a los sujetos que deberían acogerla ${ }^{17}$.

Por regla general, la eficacia de los códigos de conducta puede mensurarse teniendo en cuenta la posibilidad de que su actuación se plantee en clave meramente connotativa dentro de un contexto moralmente neutro, o a través de regulación privada, o mediante una mera especificación de los principios configuradores de la responsabilidad disciplinaria ${ }^{18}$. En este punto, resulta necesario establecer una relación de complementariedad entre autorregulación ética y el ordenamiento

\footnotetext{
${ }^{16}$ Así, BRUTTl, "Codici di comportamento e società quotate", en (2007) Giurisprudenza Commerciale, I, p. 253-254.

17 MAfFeitone, "Ragioni dell'impresa e vincoli morali", en (2001) Filosofia e questioni pubbliche, p. 17.

${ }^{18}$ CAfAGGI, "Crisi della statualità, pluralismo e modelli di auto-regolamentazione", en (2001) Politica del diritto, p. 552 ss.
} 
jurídico en el que se inserta. Como consecuencia de esta relación de complementariedad, los códigos pueden coadyuvar a la consecución de tres objetivos: favorecer la asimilación empresarial del núcleo axiológico contenido en el marco normativo legal; otorgar una mayor especificación de la materia legal contenida en principios generales y abstractos; y dar un mayor apoyo a aquellas medidas jurídicas sancionadoras de naturaleza reputacional.

Los códigos de conducta gozan, además, de funciones muy diversas dependiendo del ámbito económico en que vayan a operar, así como de la naturaleza normativa que típicamente regule los sectores económicos contemplados por el contenido del código. Así, por ejemplo, en la administración pública la codificación ética tiene como objetivo orientar la toma de decisiones en la denominada "área gris" de la actuación administrativa (esto es, aquel ámbito de frontera o contacto entre el Derecho privado y público). Los criterios de conducta establecidos en tales códigos reflejan, por lo general, reglas de ética pública para cuya tutela y protección resulta imprescindible substraer algunas facultades y competencias a la libre disponibilidad de las partes. En la "business community", por el contrario, las exigencias éticas establecidas en códigos de conducta, por hacer referencia a una ética privada, estriban fundamentalmente en la reducción de determinados costes transaccionales; concretamente, aquellos ligados a los objetivos empresariales que, en cierta medida, sean respetuosos con los derechos de los "stakeholders" de la empresa.

Una segunda diferencia surge respecto a las consecuencias derivadas de la infracción de los códigos de comportamiento. En efecto, como se ha puesto de manifiesto, existe un riesgo cierto de que, sobre todo en relación con los trabajadores públicos, les puedan ser imputados ciertos delitos sobre la base de la mera violación de las normas de un código. Esta consecuencia ha de evitarse a toda costa por cuanto

[u]na tal eventualidad representaría un abuso de un instrumento que sirve para prevenir (y no para probar) la comisión de un delito; la violación de un código de conducta tan sólo puede servir para dotar de contenido a las cláusulas generales y, por tanto, coadyuva en la labor de asumir valores sintomáticos de una responsabilidad penal que tiene que evaluarse a la luz de todos los elementos requeridos por la norma penal ${ }^{19}$.

En este sentido, resulta casi superfluo apostillar que se trata de un riesgo que dificilmente puede concebirse en relación con la responsabilidad civil de los gestores de la empresa.

${ }^{19}$ Así, Mattarella (2007) Le regole dell'onestà. Etica, politica, amministrazione, Bolonia, Il Mulino, p. 166. 
Pasemos ahora al análisis de los términos en que la responsabilidad social de la empresa debe adaptarse a la realidad de las sociedades de pequeña o mediana dimensión. Este aspecto de la RSE entra en conexión con muchas de las cuestiones clásicas que se afrontan en el estudio más general de la regulación de las relaciones inter-empresariales entre PYME. Veamos por qué.

En primer lugar, la presencia de una red de empresas se prefigura como el escenario económico ideal. A través de la red de empresas se supera la principal objeción tradicionalmente planteada a la autorregulación ética: la afirmación según la cual la autorregulación ética de las empresas sólo obtiene resultados positivos por depender de valoraciones de carácter puramente conservador. Esta crítica parte de la hipótesis de que en una economía de mercado resulta muy difícil prever a priori el comportamiento de las demás empresas, lo que desincentiva la estandarización en códigos de conducta de una serie de comportamientos éticamente virtuosos. Por tanto, la presencia y creación de una red de PYME puede representar un espacio privilegiado para coordinar, dentro de las conexiones empresariales dominantes, las expectativas recíprocas de los operadores económicos. La red de PYME conllevaría una reducción del nivel de incertidumbre acerca de otras intenciones reales de las empresas, sin que se produjera una oferta sub-óptima de autorregulación, derivado del problema de "adverse selection". Téngase presente que, por lo general, la reputación es un bien escaso, más difícil de adquirir que de perder ${ }^{20}$. En las relaciones inter-empresariales, por las mismas razones apenas citadas, tanto la repetición de las experiencias positivas exigidas para adquirir una buena reputación, como el número de las experiencias negativas suficientes para perderla, han de ponderarse de modo completamente distinto. A su vez, la menor interferencia que en este contexto media entre ética privada y ética pública, fundamentalmente cuando estemos en presencia de empresas de menores dimensiones, representa un argumento de más que coadyuva en nuestra pretensión al mantenimiento de un uso ventajoso de instrumentos éticos.

Con respecto a las empresas de mayores dimensiones, por el contrario, la aproximación a la "stakeholder theory" ha recibido una fuerte crítica. Se piensa que la aplicación de esta teoría reduce los dilemas decisionales por el intento de hacer prevalecer la responsabilización del "management" societario. No obstante, respecto a las estructuras prevalentes en las empresas diseminadas y en red, parece congruente entender que el propietario de la sociedad puede revestir el papel auspiciado de "árbitro de la moralidad". Así, el socio gestionaría con mayor libertad

${ }^{20}$ SACCONI (1991) Etica degli affari: individui, imprese e mercati nella prospectiva di un'etica razionale, Milán, Il Saggiatore, p. 350. 
y discrecionalidad las relaciones empresariales, lo que disminuye las interferencias que puedan surgir entre los distintos grupos de "stakeholders" en el momento en que sea necesario elegir entre tipologías éticas de diferente naturaleza.

Al mismo tiempo, se hace preciso analizar la difusión de prácticas socialmente responsables en el ámbito de redes "non-profit" (independientemente de que hayan sido constituidas por entes a su vez "non-profit" o por entes lucrativos). En este contexto, el sistema de incentivos a la participación de los "stakeholders" en el ente de referencia se fundamenta sobre los efectos esencialmente reputacionales que posiblemente se derivan de dicha participación. Estos efectos reputacionales son mayores frente a lo que sucede en las empresas lucrativas, por la extrañeza que supone en la cultura del "non-profit" la inserción de dinámicas de carácter propietario entre las empresas co-interesadas en red. Una estructura de este tipo puede desarrollar, a su vez, funciones de regulación del sistema de responsabilidad social, lo cual resulta preferible por el recurso a una organización de red dotada de subjetividad jurídica propia ${ }^{21}$.

En cualquier caso, independientemente de la forma jurídica elegida, se pueden identificar y diferenciar tres diferentes instrumentos de autorregulación: los códigos de autorregulación de empresas individualmente consideradas (cuya función principal es la de dotar a la organización de cierta racionalidad); los códigos de autorregulación ética lque desempeñarían fundamentalmente una función de integración de la disciplina de sistemas); y los códigos de autorregulación de la red (principalmente con funciones constitutivas de la red a través de instrumentos "soft" que permitan preservar el justo equilibrio entre formalidad e informalidad) ${ }^{22}$.

Pese a esta complejidad, los instrumentos autorregulatorios realizan, a su vez y de forma indirecta, funciones de precisión de la identidad organizativa del ente, reduciéndose así los riesgos de isomorfismo -típicos de los entes "non-profit"-y la pérdida de eficacia organizativa y decisional que sufren normalmente estos entes. Además, los códigos éticos pasan a integrarse en las estructuras de "governance" de aquellos entes que lo hayan adoptado, estableciendo asimismo sistemas de

${ }^{21}$ CAFAGGI-IAMICEL, "Le reti per la regolazione della responsabilità sociale", en AA.VV. (2005) Guida critica alla responsabilità sociale e al governo d'impresa: problema, teorie e applicazioni della CSR, dir. Sacooni, Roma, Bancaria, p. 454-457.

${ }^{22}$ Con respecto a la autorregulación de las empresas sociales véase GALLETI-BOSI, "Forme giuridiche", en Demozzi-Zandonal (2008) Impresa sociale di comunità. Strumenti per la creazione e la gestione, Trento, Edizioni 31, p. 167 ss. 
"accountability" de la organización frente a los propios "stakeholders", merced al uso de supuestos de hecho e instituciones del derecho societario ${ }^{23}$.

En conclusión, la impostación contractualista del interés social impide determinar "ex ante" el haz de valores e intereses adscritos al ámbito de la responsabilidad social de la empresa, heterodeterminados por el respeto a los valores humanos (en sentido lato), a menos que la tensión dialéctica entre accionistas y "stakeholders" se reconduzca a través de una valoración diferente de la llevada hasta ahora, y pueda tener su reflejo en los estatutos sociales (principal instrumento autorregulador de la empresa). Al mismo tiempo, esta apuesta por la autorregulación excluye la actuación del derecho positivo en la función de modelar legalmente los parámetros de conducta ética de los gestores societarios.

\section{La ética de empresa}

El siguiente punto en nuestra investigación estriba en el análisis del concepto de ética de la empresa. Para ello, partiremos del estudio de la dimensión del gobierno societario, haciendo especial hincapié en la doctrina "stakeholder oriented" por su mayor alcance, significación y profundidad. Será necesario, pues, presentar algunos hitos dignos de mención, así como las críticas que han recibido. Antes de ello, sin embargo, debemos re-evocar aunque sea brevemente la especificidad de la "stakeholder theory". Se ha señalado que se trata de una teoría desarrollada no sólo-o, mejor aún, no tanto- por la contribución de juristas, sino también por sociólogos y economistas y, particularmente entre estos últimos, por los exponentes del denominado "management economics", así como por organizaciones empresariales. Se ha apuntado, a su vez, que existen múltiples versiones más o menos desarrolladas de esta teoría, unas de carácter excluyente (teoría exclusiva), otras de carácter genérico (teoría inclusiva).

Entre quienes han contribuido a introducir el concepto de "stakeholder management" en la literatura económico-empresarial ha de citarse, de forma preferencial, a Edward Freeman (su obra "Strategic Management: A Stakeholder Approach", en 1984, es de referencia prioritaria). Según este autor, por "stakeholder" debe entenderse cualquier grupo o individuo que pueda influenciar (o se vea influenciado por) la obtención de los objetivos de una empresa. No obstante, es necesario recordar que

${ }^{23}$ SACCONI, "Impresa non profit: efficienza, ideología e codice etico", en AA.VV. (2002) Modelli di governo, reforma dello statu sociale e ruolo del terzo settore, dir. CARAGGI, Bolonia, II Mulino, p. 259. 
existen, a su vez, versiones muy diferentes de la noción de "stakeholder". Así, por ejemplo, hay quien distingue entre "stakeholders" primarios y secundarios, según se haga referencia a categorías de sujetos sin cuya participación en la actividad empresarial no podría sobrevivir la sociedad mercantil, frente a otros sujetos que, si bien es lo cierto que ejercen cierta influencia sobre la actividad societaria 0 , incluso, se encuentren verdaderamente involucrados en ella, sin embargo y pese a ello no pueden reputarse esenciales para la vida social. Una aproximación alternativa es aquella que fundamenta la diferencia entre unos grupos de "stakeholders" y otros a través de la conceptualización operada por Freeman. Para este autor, en las relaciones empresariales el poder de cada grupo de "stakeholders" tiene carácter de atributo individual y personalizado. El poder de cada uno se podría definir de forma distinta e individualizada, como una variable dependiente del nivel de condicionamiento recíproco que en cada contexto aúna la empresa con los "stakeholders", no pudiendo generalizarse al resto de "stakeholders".

Dejando a un lado estas cuestiones conceptuales y prosiguiendo con nuestro razonamiento, resulta interesante traer a colación el carácter específico de la "stakeholder theory" en los términos en que han sido analíticamente expresados por T. Donaldson y L.E. Preston ${ }^{24}$. Según la opinión de estos autores, en la taxonomía del concepto de "stakeholder management" se reconocen valores contextuales de carácter descriptivo, instrumentales y normativos. El valor descriptivo hace referencia al modo de funcionamiento de la empresa que opere bajo una forma societaria, en el sentido de que pone su centro de atención sobre una determinada cuestión: si y cómo las organizaciones toman en consideración los intereses de los propios "stakeholders". Por su parte, el valor instrumental estriba en el nexo que une - caso por caso - la práctica gestora de la sociedad y la consecución de los objetivos de "performance" empresarial, poniendo de relieve los mecanismos e instrumentos que podrían emplearse a fin de favorecer la obtención de tales objetivos. Pero es sobre todo el valor normativo lo que interesa a la finalidad de nuestra investigación. Esta dimensión del "stakeholders management" permite la individualización y concreción de aquellos valores a los que debería apelar el "manager" societario a la hora de gestionar las relaciones societarias con los "stakeholders", intentando superar una visión meramente representativa de la fisiología empresarial. A esta teoría le ha sido imputada (sobre todo) una precisa connotación ética, desde el momento en que es construida mediando criterios normativos que conjugan la dirección económica con la ética.

\footnotetext{
${ }^{24}$ Donaldson-Preston, The Stakeholder Theory of the Corporation: Concepts, Evidence, and Implications, en Academy of Management Review, vol. 20, n. 1, p. 65 ss.
} 
Esta última idea merece ser brevemente desarrollada, puesto que apunta una vía de investigación de las organizaciones empresariales que -en su interpretación más radical- pretende concebir la empresa como una verdadera estructura democrática, en donde el conjunto de los "stakeholders" puede parangonarse a lo que en la concepción clásica de la democracia representa la noción política de "pueblo". Esta teoría, por tanto, está impregnada de una cabal connotación políticoeconómica, que tiene la virtualidad de plasmar en un modelo teórico el paso de una concepción de la responsabilidad de empresa sustancialmente organicista, basada en la relación entre dirigentes y "stockholders", a una liberal-democrática fundamentada en la relación entre "stakeholders" 25.

Ahora bien, esta visión radical presenta algunos déficits, concentrados sobre todo en el esfuerzo que realiza para explicar la necesidad de democratizar la empresa, importando al ámbito empresarial la cosmovisión propia de un modelo teóricopolítico. Concretamente, tales dificiencias argumentativas se hacen más evidentes cuando se compara la visión ético-empresarial con la teoría del contrato social de John Rawls. En efecto, para Rawls, el fundamento del contrato social reside en la idea de que

el consenso democrático se apoya sobre un contrato virtual entre las partes sociales. Así, una sociedad política está moralmente legitimada si y sólo si la práctica del gobierno se corresponde, en línea de máximos, con un hipotético acuerdo que podría recaer sobre determinados activos de las instituciones más importantes ${ }^{26}$.

El contrato social, por tanto, representa un paradigma virtual de comportamiento que ha de ser compartido entre "management" y "constituencies" de la empresa. Este acuerdo paradigmático operaría a nivel macro, como un recurso heurístico al que podemos reenviar los contratos sociales verdaderamente estipulados en las diversas realidades empresariales ${ }^{27}$.

Por otra parte, como antes habíamos apuntado esta teoría posee también una cabal connotación ética. Añadamos ahora algún detalle más. La denominada "stakeholder perspective" (que, respecto a otros modelos, necesita de mayor rigor científico, en lo relativo a su labor de identificar con mayor precisión las relaciones

\footnotetext{
${ }^{25}$ Maffettone, (nota 19), p. 8.

${ }^{26}$ Ibidem, p. 7.

${ }^{27}$ Véase, ahora, D'ORAzıO, "Etica manageriale, istituzioni e organizzazioni. Introduzione al processo disciplinare etico nelle imprese", en (2002) Filosofia e questioni pubbliche, p. 71.
} 
entre empresa y sus "constituencies") se articula a su vez en diversos enfoques, cada uno de los cuales, en realidad, son visiones subyacentes de la empresa, aunque muy diversas entre sí. De forma esquemática, Freeman realiza un enfoque multifiduciario de la empresa, basado en la consideración de que sobre el manager pesa una verdadera obligación de carácter fiduciario frente a los "stakeholders" de igual importancia y valor jurídico que las debidas a los "shareholders". Por el contrario, siguiendo una aproximación estratégica, hay quien entiende que los "stakeholders" sólo constituyen sin más una serie de sujetos que el "manager" debe saber gestionar de forma instrumental al fin de lograr lo verdaderamente importante que no es otra cosa sino únicamente la consecución de los objetivos empresariales (o, lo que es lo mismo, el mantenimiento de la empresa a lo largo del tiempo). Finalmente, el enfoque ecléctico propuesto por la "new stakeholder synthesis" entiende que si bien es lo cierto que las empresas tienen verdaderas obligaciones frente a los "stakeholders", estas obligaciones, empero, no son de naturaleza exclusivamente fiduciaria, sino que tan sólo consisten y se reconducen, en su mayor parte, al respeto del deber de buena $\mathrm{fe}^{28}$.

Con respecto al modelo de desarrollo y de regulación de la actividad de empresa propuesto por Freeman, aparece singularmente apropiado traer a colación la síntesis realizada por Emilio D'Orazio:

La "stakeholder view" de la empresa defendida por Freeman (...) se contrapone al modelo convencional "input-output" de la empresa por la cual ésta se concibe principalmente como una actividad económica en la que los recursos económicos se obtienen con el fin de conseguir beneficios para el propietario/accionista: inversores, trabajadores y proveedores proporcionan "inputs" que la empresa transforma en "outputs" en y para beneficio de los consumidores. En el modelo de los "stakeholder", la empresa, por el contrario, viene concebida no sólo como una serie de transacciones de mercado, sino como un esfuerzo cooperativo (y competitivo) que involucra a un amplio número de individuos y grupos organizados de diversa manera. La empresa es, por tanto, una organización en la que (y a través de la que) muchos individuos y grupos diferenciados intentan obtener fines que les son propios. Una empresa interactúa continuamente con los propios "stakeholders" y gran parte de su éxito depende de cómo todas estas relaciones se gestionan. Gestionar relaciones con los "stakeholder", antes que "input" $y$ "output", puede ofrecer, en efecto, un modelo adecuado para comprender cómo se comportan y cómo deberían comportarse los individuos en la empresa ${ }^{29}$.

\footnotetext{
${ }^{28}$ D'ORAZIO, (nota 29), p. 70.

${ }^{29}$ Así, D'ORAZIO, "Verso una teoria degli stakeholder descriptiva: modelli ad uso dei manager di organizzazioni complesse", en (2005) Notizie di Politeia, p. 13.
} 
A partir de estas conclusiones emerge un criterio ecléctico de carácter estructural, que ha sido calificado como una tercera aproximación; si bien, sólo puede ser identificada de forma abstracta, mediante modelos ideales. Según esta concepción, la "stakeholder theory" se encuentra connotada no sólo por valores de naturaleza ética (como hemos tenido ocasión de apuntar), sino también por valores de naturaleza fundamentalmente jurídica. En consecuencia, las instituciones de derecho societario deben considerase instrumentos que necesariamente tienen que concurrir para garantizar su puesta en práctica y su respeto.

Con todo, la "stakeholder theory" no está exenta de serias críticas ${ }^{30}$, tanto desde el punto de vista ético, como jurídico que merecen ser atendidas. Veámoslas en este mismo orden.

Una primera y bien argumentada crítica estriba en el hecho de que el equilibrio de los intereses adscribibles a las diferentes clases de "stakeholders" representa una de las claves con la que la gestión empresarial debe amoldar su actuación. Este hecho, por lo tanto, carece de las características intrínsecas de toda elección moral que se manifiesta en la ordinaria discrecionalidad de los "managers" a la hora de administrar la sociedad. No muy lejos de este razonamiento se encuentra el convencimiento según el cual la "stakeholder theory" aparece cuanto menos redundante, en la medida en que la necesidad de considerar los intereses de los distintos grupos de influenciados por la empresa forma parte del conjunto de motivaciones estratégicas que guían a los gestores. Un segundo orden de críticas hace referencia a la dificultad práctica a la hora de contemplar los beneficios de las diversas clases de "stakeholders" en términos generales. Al mismo tiempo, desde un punto de vista técnico-jurídico, se ha apuntado que el concepto de equidad conduce a admitir que el trato equitativo a todos los interlocutores y afectados en y por la empresa no conlleva irremediablemente un trato igualitario. Se puede concluir, por tanto, que la "stakeholder theory" es una teoría sustancialmente superflua por dos razones: por ser difícilmente aplicable sin incurrir en contradicciones y conflictos (si se entiende en sentido lato), o por duplicar prescripciones normativas ya existentes, no adscribibles ni a instancias de naturaleza puramente éticas ni jurídicas (si se entiende en sentido estricto).

Pese a tales críticas, la doctrina "stakeholder oriented" ha tenido el mérito de influir e incidir en los estudios jurídicos realizados en materia de "corporate governance", induciendo a la literatura especialista al menos a interrogarse sobre los términos

${ }^{30}$ LA TORRE (2009) Questioni di etica d'impresa. Oltre I'homo oeconomicus, Milán, Giuffrè, p. 107 ss. 
en los que esta visión de la empresa puede encontrar expresión jurídica positiva de forma congruente en el seno del ordenamiento jurídico italiano. Así y pese a que esta propuesta interpretativa ha sido incisivamente estigmatizada, no cabe desconocer, sin embargo, que ha influido en el desarrollo de un debate extremamente provechoso acerca de la cuestión exclusivamente jurídica de la compatibilidad entre la razón económica y razones éticas y su inserción en aquella parte del ordenamiento jurídico que afecta a la realidad empresarial. Veamos qué nivel de éxito ha obtenido esta teoría.

La doctrina iusmercantilista ha intentado dar respuesta al siguiente interrogante: ¿qué supuesto de hecho y qué instituciones de derecho societario -suponiendo que existan- han de tomarse en consideración para lograr el objetivo de vincular una sociedad capitalista a la persecución objetivos de responsabilidad social en relación con los propios "stakeholders"? Es necesario dividir la respuesta en dos planos. Sobre el plano de un razonamiento abstracto es posible encontrar más de un complejo de normas de las que se pueden extraer propuestas interpretativas que se muevan en la dirección deseada. Por ejemplo, nos encontramos con las normas que regulan el régimen de la actuación discrecional gestora y de la responsabilidad de los administradores, los límites o las posibilidades de la autonomía estatutaria para configurar las relaciones intrasocietarias y los poderes de la junta general o, incluso, la utilización de modelos alternativos de gobierno societario. Por otra parte, debe recordarse la orientación mencionada anteriormente (sub § 2 , nt. 2) relativa al convencimiento doctrinal y jurisprudencial dominante acerca del hecho de que el interés de la sociedad mercantil no puede coincidir con el de los propios accionistas $y$, específicamente, no puede identificarse con el conjunto de intereses del socio (incluso aquellos en conflicto recíproco con el interés de los demás socios) en cuanto parte del contrato social.

A partir de esta consciencia, se han apuntado múltiples objeciones sobre la base del régimen concreto de cada realidad societaria ${ }^{31}$. De entre estas objeciones, que sólo podemos recordar brevemente en este estudio, destaca la opinión según la cual los administradores no pueden de ninguna manera adoptar acuerdos contrarios a los intereses de los socios, a menos que se trate de decisiones que, a largo plazo, también puedan beneficiarles. Además, debe recordarse la razón por la cual la prohibición de delegar facultades gestoras a la junta general, introducida por la reforma del Derecho societario italiano de 2003, representa el repudio más manifiesto e inequívoco a la aplicación de la teoría institucionalista de la sociedad

${ }^{31}$ Por todos cfr. Costi, (nota 13), p. 98 ss. 
en ese ordenamiento jurídico. Asimismo, se considera nulo por ilicitud del objeto el acuerdo de la junta general que asigne a terceros los beneficios de la sociedad, incluso cuando fuese acordado mediando el voto unánime de todos los socios, en cuanto contradice lo dispuesto en el art. 2247 del Código civil italiano ${ }^{32}$. Finalmente, nos encontramos con la opinión según la cual no es lícito imponer a los consejeros de la sociedad estructurados a través de un sistema dualístico de administración y control deberes relativos a la responsabilidad social de la empresa, puesto que los miembros del consejo de vigilancia no son nombrados por los "stakeholders", ni menos aún se exige que se motive expresamente la elección entre los modelos gestores -tradicional y dualístico-. Y así podrían citarse otras conclusiones distintas del mismo tenor.

Como conclusión, resulta de interés traer a colación la contribución de quien ha entendido que, en el seno de las cuestiones que aquí se abordan, resulta obligatorio individualizar un problema objetivamente complejo, merecedor como tal de una atenta consideración sujeta a posteriores interpretaciones como consecuencia de las distintas orientaciones jurisprudenciales que posiblemente existirán en este punto ${ }^{33}$. Francesco Denozza reconoce que es necesario limitar la discrecionalidad de los "managers" para evitar que se les puedan imputar las naturales consecuencias de cualquier elección gestora que "a posteriori" se revele errónea. Si a ellos se les exigiese soportar este nivel de riesgo, ya "per se" enorme, en relación con cada decisión que afectase a las distintas clases de "stakeholders" de la empresa, esa exigencia comportaría una ampliación inaceptable de su poder discrecional, por una parte, $y$, por otra, la consecuente asunción de responsabilidad por daños. Este efecto, empero, puede resultar atemperado teniendo en cuenta que el juez, a la hora de escrutar la actuación de los "managers", realiza un juicio "ex ante" sobre la normal inherencia (y coherencia) del acto gestor al contexto empresarial en que se desenvuelve la administración social, es decir, el juez individualiza un haz de actos que se corresponden a un hipotético "standard" de diligencia, determinado sobre la base de un criterio de normal consecuencialidad ${ }^{34}$. Por otro lado, probablemente va a prevalecer la opinión doctrinal contraria a la defensa (y anhelo)

\footnotetext{
32 Según el art. 2247 Código civil italiano con el contrato de sociedad dos o más personas aportan bienes o servicios para el ejercicio en común de una actividad económica al objeto de dividir las ganancias.

${ }_{33}$ DenOzZA, "Bilanciamento degli interessi e discrecionalita dei gestori", en Guida critica alla responsabilità sociale e al governo d'impresa, (nota 23), p. 151 ss.

${ }^{34}$ Rossl, "Artt. 2392-2394-bis", en AA.VV. (2005) Il nuovo diritto delle società, dir. MAfFel AlberTI, I, Padua, Cedam, p. 790 ss.
} 
por la responsabilización social de la empresa. Y esto -sólo- sobre la base del número excesivo de los criterios que habrían de aplicarse y tenerse en cuenta para equilibrar los diferentes grupos afectados por la empresa y para valorar desde este plano la congruencia de las elecciones gestoras de los "managers".

Asimismo, Denozza pone de manifiesto la insatisfacción de la tesis que entiende que la tutela de los terceros, mejor dicho, de sujetos distintos de los socios, debe confiarse únicamente a las garantías ofrecidas por los contratos que la empresa estipula con ellos (contratos que son expresados en términos fisiológicamente incompletos), además del respeto de las obligaciones legales (que son expresados en términos necesariamente generales). En cualquier caso, no puede desconocerse que en el seno de las sociedades capitalistas se establecen (de hecho) verdaderos equilibrios entre los intereses de los socios y los intereses "de otros". Lo cual sigue siendo verdad aun cuando esta ampliación de la responsabilidad de los gestores tenga lugar sobre la base de motivaciones puramente eficientistas $y$, como tales, no desarrolladas apriorísticamente como consecuencia de la implantación de verdaderos instrumentos de responsabilidad social de la empresa. Si estas consideraciones aparecen convincentes, se debe tener presente además que

la cuestion de la responsabilidad social de la empresa debe encontrar su espacio, salien-

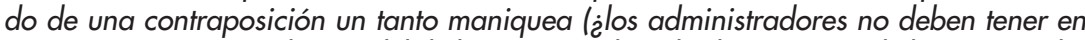
cuenta ningún interés distinto del de los socios o de todos los intereses de los potenciales interesados?) y comenzar a establecer las oportunas distinciones entre intereses sociales que-parezcan- sean más eficazmente protegidos a través de vínculos externos e intereses, cuya protección puede incrementarse mediante la imposición de un vínculo interno; o entre intereses que pueden encontrar mejor acomodo en el interior de los órganos sociales (como es el caso de ciertos intereses de la comunidad fácilmente confiable a sujetos nombrados por organizaciones tales como sindicatos o entes públicos territoriales) e intereses más institucionalmente externos (protección de derechos humanos, tutela del medio ambiente, etc.). Quizás, escapando de una contraposición indiferenciada entre intereses de los socios por una parte e intereses del resto del mundo por otra, podría partir una vía experimental que comenzase a introducir la protección de algún específico interés general entre aquellos objetivos que debería perseguir una moderna organización de la denominada "corporate governance"

Respecto a esta cuestión nos adherimos al análisis y representación exhaustiva que Renzo Costi ha llevado a cabo-como se ha expuesto- en lo relativo a la relación entre legítimo recurso a los instrumentos del derecho societario y posibilidad de responsabilización de los gestores en relación con los "stakeholders" de la empresa. Dicho esto, nos parece que el punto evocado por Denozza poseía el mérito de

${ }^{35}$ Así, Denozza, (nota 35), p. 155-156. 
llevar a cabo una necesaria concreción (si bien, en el momento en que se escribe, sólo se ha realizado de forma parcial) relativa al modo específico en que se puede conferir equidad, eficiencia y certeza al derecho societario, otorgando plena validez a los códigos de autorregulación que la empresa quisiera dotarse. Es el argumento que se trata en el parágrafo que sigue.

\section{La autorregulación societaria}

Como hemos puesto de manifiesto, las corrientes doctrinales defensoras de la responsabilidad social de la empresa y, más concretamente, la doctrina "stakeholder oriented" han puesto en seria prueba al Derecho societario. En ambos casos, estamos ante propuestas interpretativas que contienen una connotación y cosmovisión ética de la realidad empresarial. A su vez, en ambos casos, la doctrina iusmercantilista ha respondido en términos sustancialmente negativos a la posibilidad de "contaminar» el Derecho societario de ética. Sin embargo, resulta evidente que esta contra-reacción iusmercantilista debe superarse habida cuenta del carácter limitativo de las convicciones en que se sustentan. No se puede aceptar, sin más, el mito de la imposibilidad e impermeabilidad absoluta del régimen jurídico afectante a la empresa para acoger valores de naturaleza "ética" (entendida, ahora, en sentido lato). A su vez, se tiene la convicción de la oportunidad, conveniencia y urgencia de llevar a cabo la «experimentación» invocada por Denozza. En opinión de quien escribe, es necesario adoptar una aproximación diferente a la cuestión de la ética de la empresa, que adopte una visión de carácter estructural, de forma tal que pueda verificarse en qué medida el Derecho societario sirve para la introducción de componentes éticos en la empresa aunque sea de forma indirecta, esto es, sin entrar en conflicto directo con los parámetros positivizados legalmente.

En líneas generales, podemos señalar que la reflexión sobre conceptos de empresa ética y de ética de empresa, en su conjunto, ha condicionado el derecho societario del modo siguiente.

Se pueden distinguir dos líneas de influencia, aunque tan sólo nos limitaremos a analizar algún ejemplo, comenzando por el aspecto atendiente a la autorregulación de la actividad de empresa. La consolidación del debate respecto de la ética de los negocios ha llegado a convencer cabalmente a la doctrina jurídica acerca de la oportunidad de confiar (en mayor grado respecto a cuanto se hacía en el pasado -incluso reciente- de la legislación iusmercantilista) en las ventajas que pueden desprenderse de la ampliación de los confines dentro de los que se manifiesta la autonomía organizativa de las sociedades de capital. Se ha adquirido la 
consciencia de la utilidad de incentivar a las empresas por dotarse de modelos de autorregulación (no sólo de carácter estatutario, que también). Modelos que no tienen por qué ser uniformes, ni estar homologadas a ciertas prácticas societarias preconstituidas. Por el contrario, se ve la oportunidad de que los modelos de autorregulación den lugar a la máxima diferenciación posible entre las empresas, favoreciendo así el desarrollo de dinámicas concurrenciales entre los posibles y futuros inversores en el capital de aquellas sociedades que cuenten con modelos de autorregulación de carácter ético.

No obstante, como consecuencia de esta toma de consciencia, se ha afirmado la plena necesidad de incorporar en el ordenamiento jurídico italiano un mayor grado de regulación dispositiva, adecuada para la regulación de la actividad de empresa. Téngase presente que los costes de transacción en los que típicamente incurren las sociedades de capital hacen inoportuno, por no decir imposible, la definición por vía negocial de cada aspecto requerido de regulación. Por tanto, urge la necesidad de contar con reglas jurídicas adaptables a las exigencias de los distintos contextos, que puedan ser moldeables por parte incluso de los propios sujetos llamados a someterse a ellas. Nos referimos, en efecto, a las normas de "default", esto es, a normas que tienen vigor jurídico y, como tales, integran el contrato societario en tanto en cuanto los contratantes no predispongan una disciplina alternativa a aquella dispuesta por la misma norma. En esta perspectiva,

bien se justifica (...) el escepticismo con el que el modelo contractualista mira a las reglas imperativas; desde el momento en que impone la aceptación indiscutible de una ayuda ofrecida por un tercero respecto a la relación contractual -vale a decir el "rule maker" institucional- aparece una disonancia difícilmente justificable ${ }^{36}$.

Por otra parte, por las mismas razones, parece evidente que un cierto grado de imperatividad normativa no sólo es útil, sino imprescindible.

La segunda línea de influencia es la relativa a la heterorregulación de la actividad de empresa. El recurso a "standards" contenidos en cláusulas generales se ha consolidado como una técnica regulativa eficaz. Este recurso permite cumplir funciones distintas respecto a las tradicionales y posibilita, a su vez, asegurar, entre otros, objetivos de coherencia y uniformidad a modelos organizativos entre ellos muy diversos ${ }^{37}$. Esta función de coordinación que aplica diferentes

${ }^{36}$ Así, MARChetti (2000) La "nexus of contracts" theory. Teorie e visioni del diritto societario, Milán, Giuffrè, p. 153-154.

${ }^{37}$ Así, CAFAGGI "Riforma de diritto societario: il ruolo delle "clausule generali»", en (2001) Stato e mercato, p. 61 
modelos de gobierno societario se manifiesta merced al papel que las cláusulas generales pueden jugar frente a los "stakeholders" de la empresa. Cierto es, en efecto, que el terreno más tradicional de aplicación y utilidad de las cláusulas generales es el relativo a la aplicación judicial como consecuencia de posibles controversias surgidas en las relaciones intrasocietarias. Sin embargo, no cabe la menor duda de que progresivamente está emergiendo la necesidad-además de la oportunidad- de predisponer instrumentos regulatorios cuyo valor normativo "cubra" también el ámbito de los intereses de las relaciones extrasocietarias, esto es, relaciones con terceros (ajenos a la propiedad de la empresa) y con acreedores de ésta, a fin de evitar posibles efectos distorsionadores, mediante un régimen jurídico totalizador que abarque plenamente la actividad de una determinada empresa.

Son múltiples las razones que ponen de manifiesto la progresiva necesidad de regular de forma innovadora las relaciones con los "stakeholders". A este fin, el recurso a "standards" e instrumentos de autorregulación representa una solución viable. Entre otras razones conviene recordar, al menos, la transformación organizativa que ha afectado a gran parte de las empresas italianas como consecuencia de la reticularidad de sus propias relaciones. Esta transformación hace patente la interdependencia que existe entre las actividades económicas desarrolladas por diversas empresas -que forman más o menos parte de un ámbito productivo único y común, como tradicionalmente tiene lugar en los contextos distrectuales-y los co-intereses de categorías de "stakeholders", aun cuando se encuentren ligados directamente a empresas diferentes. Estas características cuentan con serios problemas regulatorios, por ejemplo en relación con las exigencias de equidad y eficiencia, que pueden ser adecuadamente encauzados mediante el recurso a los mencionados instrumentos de "soft-law", así como confiando en un comportamiento por parte de la jurisprudencia que se muestre igualmente sensible a tales transformaciones económicas y jurídicas.

De forma más particular, podemos individualizar dos planos de aplicación de las citadas instancias de cambio, atendientes respectivamente a los modelos de autorregulación empresarial y a los modelos de autorregulación societaria ${ }^{38}$. La línea de demarcación entre ambos modelos puede trazarse entre aquellos que inspiran los códigos adoptados por sociedades de mediana-pequeña y de gran dimensión -respectivamente-. Examinémoslos por separado.

\footnotetext{
${ }^{38}$ Sobre este punto consiéntase el reenvío a Bosl (2009) Autoregolazione societaria, Milán, Giuffrè, passim.
} 
Consideraremos fundamentalmente los modelos de autorregulación empresarial. Se trata de modelos que permiten hacer frente, por un lado, a la formación parcial de los costes de contratación y de organización empresarial, propiciando con ello una asignación residual de los derechos de control más eficiente respecto a la realizada por la vía contractual. Por otro lado, proporcionan un cálculo exhaustivo de la asignación de los riesgos en las relaciones contractuales de larga duración, atemperando los costes derivados de los abusos de autoridad que pueden producirse en el interior de la empresa. Existe una relación directa, sintética y convergente entre la autorregulación negocial y el hecho de que el "manager", en relación con los "stakeholders", viene sujeto por verdaderas obligaciones jurídicas que se desprenden no sólo por la vigencia de cláusulas de correcto comportamiento, sino por verdaderos vínculos de naturaleza fiduciaria, en los mismos términos en los que se encuentra responsabilizado mediante obligaciones y vinculaciones análogas en relación con los accionistas. Veamos en qué términos se concreta este nexo.

Las funciones de los modelos en examen, derivados de la lectura jurídica que estudia los modelos de "management by objectives", se llevan a cabo en una disciplina connotada por la polivalencia. Así pues, la autorregulación empresarial, antes que para la interiorización de directrices de comportamiento, sirve para la ramificación de las posibilidades regulatorias puestas a disposición discrecional del decisor managerial. A tales modelos se les puede imputar, por tanto, una función de "up-grading" normativo de los "standards" que derivan de fuentes externas de "benchmarking" y de "best practices", por los códigos éticos "de primera generación" y por códigos deontológicos. Su estructura, adscrita al paradigma conocido como "neo-contractualismo", no puede dejar de ser, por tanto, una construcción polisistémica y compleja, connotada de sincretismo normativo y fisonomía modular, en la que convergen "benchmarks" fijos y disposiciones elásticas, normas inderogables y dispositivas. O sea una estructura que permita dotar de coherencia normativa elementos diversos: disposiciones destinadas a incidir inmediatamente sobre el contenido de los contratos de suministro; cláusulas de salvaguardia relativas a las fases patológicas de la relación; incentivos al "commitment" recíproco por parte de los contrayentes; parámetros de buen comportamiento, etc.

Parece evidente que, como consecuencia de los elementos típicos de la estructura en red de relaciones inter-empresariales, la autorregulación puede asumir valores originales, de carácter no exclusivamente combinatorio e igualitario, En efecto, la estructura empresarial en red hace que las distintas estrategias empresariales se predispongan de tal manera que conjugan una multitud de instancias y valores nacidos como consecuencia de relaciones multidireccionales, de naturaleza fiduciaria o no. Así, la autorregulación resulta de gran utilidad a estos fines pues 
es capaz de aprovechar aquellos instrumentos societarios que se muestren más idóneos para incidir sobre la estructura organizativa de los sistemas internos de control relacional. El modelo de autorregulación empresarial sirve, por tanto, como una verdadera fuente de obligaciones con distinto carácter vinculante en relación a específicas exigencias. Así, puede establecerse un código de autorregulación empresarial, en aplicación del modelo, como instrumento de carácter no continuo pero discreto, que ponga de manifiesto principalmente el hecho del recurso paralelo a instituciones de "soft-law".

En este sentido, es necesario dedicar una específica atención a los aspectos negociales conectados con el mantenimiento de relaciones de duración con los "stakeholders" de referencia, en una óptica de investigación de la cooperación entre los sujetos cointeresados y de realización contextual de la transición "from status to contract" 39 .

Una primera aplicación de gran calado del modelo descrito lo representa el contrato de red, positivizado en el ordenamiento italiano merced a la promulgación de la Ley de 8 de abril de 2009, n. 3340. El contrato en red es un contrato "transtípico" al que se le atribuyen objetivos de incremento de la capacidad innovadora y competitiva de las empresas, en un ámbito jurídico al que se atribuyen determinados valores dirigidos a favorecer de forma más inmediata la colaboración inter-empresarial y la coordinación de actividades empresariales para la persecución de algunos objetivos estratégicos compartidos. La coherencia de semejante herramienta negocial, que comparte las características del modelo de autorregulación empresarial que hemos expuesto, emerge en el momento en que se considera que

la individualización de un supuesto de hecho "transversal" a los tipos normativos y a los tipos sociales, incluso a aquellos que la praxis generará en el futuro siguiendo la estela del contrato de red, se encuentra en la ampliación de la flexibilidad de las elecciones operativas, situándose, en caso de necesidad, más allá de los vínculos representados por la mutualidad, por la auxiliariedad de la actividad de la red en comparación a la de los adherentes, por una "función de servicio" general a la que se circunscribe la operatividad de la red limitando de alguna manera la innovación. No sólo con el contrato de red se

\footnotetext{
39 Para la ejemplificación empírica de un contexto empresarial en el que este modelo se corresponde con las exigencias de governance de la filial y de la organización productiva local, cfr. BosIDeGASPERI, "Le reti di imprese nel distretto orafo di Vicenza", en (2007) Reti di imprese tra crescita e innovazione organizzativa. Riflessioni da una recerca sul campo, dir. CAFAGGI-IAMICEL, Bolonia, II Mulino, p. 225 ss.

${ }^{40}$ Sobre este tema véase, al menos, CAFAGGI (2009) II contratto di rete. Comentario, Bolonia, II Mulino; IAMICEL (2009) Le reti di imprese e i contratti di rete, Turín, Giappichelli.
} 
puede continuar haciéndolo, sino que se posibilita a las empresas crecer sin que sea necesario compartir segmentos de actividad (las denominadas "fases" coordinadas en el consorcio), sino tan sólo competencias, capacidades proyectadas, riesgo de empresa, adaptando a tal programa el funcionamiento de las empresas de derivación (si bien en los límites del denominado objeto social) y no al contrario ${ }^{41}$.

Pasemos ahora a analizar los modelos de autorregulación societaria. Ellos representan la matriz de los códigos de autorregulación societaria, códigos que -a su vez- en Italia viene identificados con los códigos denominados de autodisciplina, equivalentes a los "codes of corporate governance" de los estados anglosajones (donde fueron utilizados por primera vez). El "Codice civile" y el "Testo Unico della Finanza" se refieren a ellos utilizando el término erróneo de "código de comportamiento"; denominación que, por otro lado -y como se ha puesto de manifiesto-, expresa una total ajenidad a valores de carácter moral ${ }^{42}$. Sin embargo, se trata de instrumentos reguladores que inciden de forma indirecta en cuestiones relevantes para la ética de los negocios de las sociedades anónimas cotizadas en mercados regulados. Intentemos a continuación explicar por qué.

En primer lugar, es posible atribuir a los modelos de autorregulación societaria un valor de reconocimiento, de carácter estático. Ese valor se sustancia en aquellas situaciones en las que el código de autodisciplina contenga una serie de directrices de gobierno societario conocidas y avaladas sustancialmente por la doctrina y por los operadores, sean jurídicos o económicos, que han coadyuvado en la constitución del modelo de autorregulación utilizado como referencia. Se trata de un valor capaz de producir fenómenos de isomorfismo normativo, capaz de favorecer la aceptación del código como consecuencia de que su composición se lleva a cabo mediante reglas que han sido reconocidas como legítimas y de enorme valor.

En segundo lugar, a los modelos examinados se les pueden atribuir, de forma alternativa, un valor ideológico, de carácter dinámico, en atención a su capacidad de provocar modificaciones en la disciplina societaria. Este valor se manifiesta como consecuencia de las características específicas del desarrollo capitalista y del tipo de actitudes propietarias que caracterizan el escenario empresarial para el que se ha elaborado un determinado modelo de autodisciplina. En efecto, por la correspondencia entre el ámbito aplicativo y el "standard" de autorregulación

${ }^{41}$ Así, IAMICEL, Dalle reti di imprese al contratto di rete: un percorso (in)cumpiuto, en idem (a cura di), op. cit., p. 32-33.

${ }^{42}$ Cfr. BosI, "Art. 124-ter", en AA.VV., Commentario al Testo unico della finanza, dir. F. VelLA, Turín, Giappichelli, en curso de publicación. 
elegido -esto es, por la mayor o menor convergencia o divergencia del modelo autorregulatorio respecto de la condición de partida- será lícito hipotizar diferentes recorridos evolutivos de "corporate governance" y contemplar cómo se van adoptando, en consecuencia, distintas directrices de gobierno societario. Se trata de un valor capaz de producir tal grado de isomorfismo coercitivo que se favorece la aceptación y cumplimiento del código sobre la base de que el código está compuesto por reglas cuyo respeto se reputa necesario para conseguir los resultados deseados conforme a algunas indicaciones legislativas, o para acceder a un "status" jurídico predefinido.

En tercer lugar, se puede individualizar un valor reflexivo, de carácter dinámico y constante. Este valor trae la consecuencia de una concepción de los códigos de autorregulación como instrumentos que necesaria y programáticamente están llamados a sufrir modificaciones sucesivas de las directrices funcionales en ellos insertos $y$, sobretodo, porque la puesta en práctica de los códigos de autorregulación se lleva a cabo de forma distinta, código a código, empresa a empresa, y no de manera rígida, común y uniforme para todos los casos. Se trata de un valor capaz de producir fenómenos de isomorfismo mimético, que favorecen una recepción y cumplimiento del código basados en el hecho de que el código de autorregulación se compone de reglas que han sido experimentadas con éxito por otros operadores económicos, mediante un proceso de "peer monitoring".

Existe -ciertamente- un riesgo real de que los códigos de autorregulación actúen siguiendo proceso de "legal irritant" en atención al ordenamiento en que se inserten. En este sentido, y cualquiera que sea el valor que prefiramos otorgar a los códigos, resulta importante distinguir, a la hora de elaborar un texto en el que se declaren principios y objetivos de referencia, entre las opciones regulatorias y la posibilidad de elección ofrecida a los usuarios del código. En efecto, desde un punto de vista estructural, el ideal autorregulatorio es aquel que ofrezca un modelo de regulación por principios, a partir de una articulación del código en principios, criterios aplicativos y comentarios -por ese orden-. Resulta, por tanto, oportuno incentivar una aplicación particular y específica, según los "standards" expuestos en el modelo del código. Se trata de una indicación conforme a los resultados que confirman cómo los transplantes de los paradigmas de "corporate governance", en estricto cumplimiento con las "best practices" reconocidas y promovidas a nivel supranacional, no producen resultados apreciables fuera de los contextos originarios, allí donde difieran sustancialmente las tradiciones jurídicas y los modelos de desarrollo capitalístico a los que se apliquen. Como consecuencia, el precio de la adopción del código consiste no tanto en la máxima adhesión posible a sus indicaciones, o en una repetición servil del modelo, sino en el hecho de que 
una tal opción de autorregulación permite integrar dos exigencias: de un lado, preserva la consecución de los objetivos reconducibles al modelo del código; de otro lado, se da la posibilidad a la empresa adoptante de llenar de significado explícito, comprensible y (posteriormente) perfectible a las propias elecciones de "corporate governance", realizándose plenamente el carácter de "reflexibilidad" de esta fuente de autorregulación.

\section{6. Ética, empresa y autorregulación en el Derecho societario español}

En España también se puede reconducir y clasificar la praxis societaria conforme a los cánones de la ética de los negocios, siguiendo el esquema planteado. Así, bajo el marco de la empresa ética se evidencian recientes evoluciones normativas de gran interés. De forma particular, es posible apreciar la progresiva compenetración de las medidas de responsabilización social con la dimensión organizativa y corporativa de la empresa ${ }^{43}$, lo que constituye una señal de integración entre parámetros éticos y gestión de los negocios sociales. Por otra parte, teniendo en cuenta el aspecto teórico del análisis hasta aquí seguido, se puede individualizar un nivel unitario sobre el que insisten las razones expresadas tanto por la doctrina económico-empresarial, como por la jurídico-mercantilista y por la teoría económica de la empresa de inspiración "coase-williamsoniana". Tal plano de reflexión coherente y común viene dado por la planificación estratégica de la organización y de la actividad de la empresa. Planificación cuya definición conceptual nos remite, a su vez, a la categoría de la fórmula empresarial, entendida como organización y canalización de los recursos mediante datos objetivos estratégicos ${ }^{44}$.

El objetivo que parece consolidarse en este contexto es, por tanto, el de definir paradigmas de "governance" que conjuguen pluralismo representativo, respon-

${ }^{43}$ Club de EXCELENCIA EN SOSTENIBIIIDAD (2001) Estudio multisectorial sobre el estado de la responsabilidad corporativa de la gran impresa en España, pp. 15-17. Un intento serio de procedimentar las prácticas de autorregulación de la conducta societaria se ha llevado a cabo mediante la Ley n. 29/2009, por la que se modifica el régimen legal de la competencia desleal y de la publicidad para la mejora de la protección de los consumidores y usuarios (BOE n. 315, sec. I, p. 112039 ss.), especialmente arts. 37-39.

${ }^{44}$ Galleti "La trasformazione dell'impresa ad opera dell'organo amministrativo", en (2003) Riv. dir. comm., I, p. 657 ss. 
sabilidad social y eficiencia en la "performance" empresarial ${ }^{45}$. A este propósito podemos señalar cómo en la actualidad es merecedor de aplauso la evolución de la autorregulación empresarial de sentido (económicamente) neocorporativo y (jurídicamente) neocontractualista, en el sentido de que la eficiencia organizativa se puede conseguir, al menos idealmente, responsabilizando a los autores involucrados en la actividad de la empresa a contribuir de una manera robusta al proceso de "rule-making", e incentivando a las instituciones locales a direccionar y favorecer este proceso (de forma idéntica a lo que sucede en todos los sistemas "autopoiéticos") ${ }^{46}$. Se trata de una prospectiva convincente para las sociedades de "capital in primis", siempre que de entre los motivos que han conducido a la difusión en España de las instancias de responsabilización corporativa se incluya el interés por crear condiciones adecuadas a fin de que cualquier empresa disponga de instrumentos reguladores que le permita enfatizar sus propias ventajas competitivas frente al resto de competidores ${ }^{47}$, sin incurrir, empero, en el riesgo de aislarse del contexto de desarrollo económico y social.

Ahora bien, no resultan del todo convincentes algunas de las experiencias reguladoras con las que este mismo país ha intentado dar concreción normativa a intuiciones propias de la "stakeholder theory" (en los términos en que la ética de la empresa ha sido tratada aquí). Se piensa, por ejemplo, en el "Code of ethics for companies" 48 y a la categorización que en él se realiza respecto de las relaciones productivas que la empresa haya llevado a cabo-respectivamente-con proveedores y clientes, sujetos competidores, sus propios trabajadores y la sociedad civil. En su conjunto, se trata de un enfoque regulador pluralista que tradicionalmente ha elaborado modelos de "ethical decision making" partiendo de la premisa de que no existen soluciones universales y resolutivas para los conflictos de naturaleza gerencial o managerial. Según esta notoria impostación teórica resulta necesario implementar una estrategia decisional que se fundamente sobre la identificación de los caracteres tipológicos de los "stakeholders" y la descripción de las relaciones que les unan (teniendo presente, también, las instituciones que crean o regulan tales relaciones); que reconozca, además, cómo puede nacer un "problema ético";

${ }^{45}$ En este sentido, un ejemplo paradigmático lo constituye la Ley de Economía Social, n. 5/2011 (publicada en el Boletín Oficial del Estado, n. 76, sec. I, p. 33023 ss.).

${ }^{46}$ Bosl, Autoregolazione societaria, cit., p. 107.

${ }^{47}$ Melé (2004) Corporate social responsibility in Spain: An overview, IESE Business School, WP n. 543, p. 4.

${ }^{48}$ InStITUTO de CONSEJEROS-AdMINISTRADORES (2006) Code of ethics for companies, Madrid. 
que individualice los valores de referencia de las instituciones relevantes; y que sepa encontrar soluciones alternativas de actuación en el entorno institucional establecido, desarrollando un plano de seguimiento de los resultados obtenidos. Este planteamiento habría puesto de manifiesto cómo de forma tendencial las relaciones entre empresas e instituciones políticas y administrativas se muestran más problemáticas que las meras relaciones inter-empresariales ${ }^{49}$. No obstante, se hace necesario preguntarse si verdaderamente trae alguna ventaja la investigación sobre los principios éticos dominantes en relación a las distintas categorías de "stakeholders", individualmente considerados. En opinión de quien escribe, se corre, en efecto, el riesgo de revelarse estéril el esfuerzo por encontrar un punto de equilibrio entre los intereses sociales y las distintas e individualizadas clases de "stakeholders", dada la seria perplejidad que conlleva cualquier predeterminación de escalas de valores, cuyo peso específico está destinado fisiológicamente a mutar y transformarse en el tiempo, además de a diferir en el espacio.

Por último, el doble aspecto -empresarial y societario (en sentido estricto)- de las prácticas de autorregulación societaria (en sentido lato) ha hecho aflorar interesantes iniciativas reguladoras. Así, dentro del primer punto de vista nos encontramos con la redacción de los "Principles of good corporate governance for unlisted companies" 50 ; mientras que del segundo grupo merece citarse el "Report

${ }^{49}$ No sorprende que se reconduzcan a las relaciones entre empresa-proveedor los problemas de naturaleza ética atinentes principalmente a la corrección en el tratamiento y a las condiciones necesarias a fin de que se conserven relaciones de colaboración a largo plazo. Además, se destaca que los principios sobre los que se inspiran tales relaciones no vienen definidos con un significativo grado de detalle. Por tanto, entre las tipologías de principios a utilizar (equidad/imparcialidad, legalidad, trasparencia, conflicto de intereses, competitividad/rentabilidad), mientras las relaciones entre empresas principalmente se examinan mediante la referencia a perfiles de equidad, una mayor variedad y especificación emerge si se centra la atención sobre los deberes de comportamiento exigidos frente a clientes y trabajadores, así como frente a aquellos deberes exigibles en las relaciones entre empresa y Estado y empresa y comunidades locales; cfr. KUJALA, "Analysing Moral Issues in Stakeholder Relations", in (2001) Business Ethics: a European Review, p. 237 ss. Este hecho puede verse confirmado sobre la base de un muestreo realizado que tiene por objeto las razones de la implementación de instrumentos de certificación ética por parte de las PYME europeas, así como por algunas de las conclusiones del informe de la Comisión Europea European SMES and Social and Environmental Responsibility, de las que puede afirmarse que la mayor parte de las motivaciones existentes en este sentido se encuentran en el intento de mejorar las relaciones con la comunidad y las autoridades públicas, más que con los "partners" empresariales y con los inversores.

50 InStITUTO DE CONSEJEROS-ADMINISTRADORES (2008) Principles of good corporate governance for unlisted companies, Madrid. 
of the special working group on the good governance of listed companies" ${ }^{\prime \prime 1}$. Es sobre todo el primer código de autorregulación el que presenta un mayor interés, por cuanto que en él se encuentran referencias explícitas -por ejemplo- a la posibilidad de modificar "in itinere" este instrumento de gobierno societario, adaptándolo en función de los diferentes contextos socio-económicos y reguladores dentro de los cuales se aplica. Sobre un análisis meramente teórico, es lícito presuponer que no se aplicarán aquellas reglas de gobierno societario que no se adapten a las especificidades de una particular tipología societaria-como, por ejemplo, sucede con las reglas de buen gobierno de empresas familiares (cfr. espec. la parte tercera del código en cuestión: "Governing bodies of the business family»)-. Téngase presente que el establecimiento de un determinado código de "corporate governance" se instrumenta con la finalidad de dotar a la sociedad de un instrumento de autorregulación conforme a unas exigencias precisas de organización y estrategia. Es más, antes que otra cosa la mera prospectiva de adoptar un código responsabiliza a la sociedad en el sentido de incentivarla a un análisis escrupuloso de las propias exigencias de "governance" interno y a las correspondientes sinergias que se generen entre tales exigencias y los aspectos del código que como consecuencia se aplicarán. Ahora bien, además de la flexibilidad, adquiere mayor relevancia, sin embargo, el significado del carácter de evolutividad, que se reconduce a la posibilidad de modificar y actualizar el código de forma periódica, mediante procedimientos menos complejos respecto a los exigidos para la revisión de las leyes ordinarias ${ }^{52}$. No obstante, el código español de autorregulación para las sociedades cotizadas ha sido configurado con un corte "clásico", en el sentido de que el carácter general de su aplicación -véase «Annex I, Unified good governance code. I. Core principles»- rechaza la posibilidad de recurrir a modalidades de autorregulación societaria inspiradas en los principios de reflexibilidad y diferenciación, anteriormente mencionados y considerados como altamente satisfactorios.

\section{Conclusiones}

Afrontando el final de este estudio, hemos de proceder a resumir el significado del análisis sintéticamente desarrollado hasta aquí.

\footnotetext{
${ }^{51}$ SPECIAL WORKING GROUP (2006) Report of the special working group on the good governance of listed companies, Madrid.

52 Bosl, op. ult. cit., p. 153.
} 
La ética de los negocios ha intentado abrir una vía de acceso en el ordenamiento jurídico societario, no sólo italiano, siguiendo principalmente dos caminos. El primero es aquel imputable a la disciplina de la empresa ética, o sea, a la regulación de la actividad de la empresa que intente obtener certificaciones de buena conducta gestora en sentido lato, desde puntos de vista mercadotécnicos, ocupacional, ambiental, etc. Es un camino por el que se ha intentado dar actuación a principios inequívocos y objetivamente apreciables, pero mediante instrumentos escasamente cogentes o imperativos y manifestándose, de hecho, improductivos sin efectos plenamente satisfactorios desde el punto de vista sustantivo.

La introducción de la segunda vía, forjada por la doctrina "stakeholder oriented" y a través de la elaboración de modelos de ética de empresa, se ha llevado a cabo intentando "agredir", ciertamente, el valor societario. Esta agresión, empero, resulta en gran medida incompatible con la concepción dominantemente contractualista de las sociedades de capital. En efecto, esta segunda vertiente ha optado por inducir y amoldar las opciones y actuaciones de los gestores de la empresa conforme a parámetros decisionales y organizativos heterodeterminados. Es un camino a través del cual se ha intentado dar juego a principios opinables, en cuanto no necesariamente compartidos por los operadores económicos interesados en aplicarlos, mediante instrumentos tendencialmente rígidos.

La primera aproximación, como hemos mencionado, ha sido y se ha verificado aún hoy modesta, mientras que la segunda ha estado en buena parte rechazada por doctrina y jurisprudencia (así como por el legislador). ¿̇Existe, aún, algún recorrido alternativo a aquellos citados para garantizar un mayor grado de eticidad en la actuación empresarial?

A juicio de quien escribe, una solución, si bien parcial, viene representada por el perfeccionamiento y por la práctica de modelos de autorregulación societaria (en sentido lato). Nos referimos concretamente a la elaboración de instrumentos de planificación y de ejercicio de la actividad de empresa que aspiran a conjugar representatividad y transparencia con el interés del gestor en mantener el propio papel de "dominus" en la definición del contenido de los códigos de autorregulación -empresarial o societaria (en sentido estricto)-. Con la mejor de las intenciones, estaremos ante instrumentos legales capaces, al menos, de garantizar-si no eticidad- equidad, eficiencia y certeza al derecho de la empresa. 